\title{
Promoting universal financial protection: evidence from seven low- and middle-income countries on factors facilitating or hindering progress
}

Di McIntyre ${ }^{1 *}$, Michael K Ranson², Bhupinder K Aulakh² and Ayako Honda ${ }^{1}$

\begin{abstract}
Although universal health coverage (UHC) is a global health policy priority, there remains limited evidence on UHC reforms in low- and middle-income countries (LMICs). This paper provides an overview of key insights from case studies in this thematic series, undertaken in seven LMICs (Costa Rica, Georgia, India, Malawi, Nigeria, Tanzania, and Thailand) at very different stages in the transition to UHC.

These studies highlight the importance of increasing pre-payment funding through tax funding and sometimes mandatory insurance contributions when trying to improve financial protection by reducing out-of-pocket payments. Increased tax funding is particularly important if efforts are being made to extend financial protection to those outside formal-sector employment, raising questions about the value of pursuing contributory insurance schemes for this group. The prioritisation of insurance scheme coverage for civil servants in the first instance in some LMICs also raises questions about the most appropriate use of limited government funds.

The diverse reforms in these countries provide some insights into experiences with policies targeted at the poor compared with universalist reform approaches. Countries that have made the greatest progress to UHC, such as Costa Rica and Thailand, made an explicit commitment to ensuring financial protection and access to needed care for the entire population as soon as possible, while this was not necessarily the case in countries adopting targeted reforms. There also tends to be less fragmentation in funding pools in countries adopting a universalist rather than targeting approach. Apart from limiting cross-subsidies, fragmentation of pools has contributed to differential benefit packages, leading to inequities in access to needed care and financial protection across population groups; once such differentials are entrenched, they are difficult to overcome. Capacity constraints, particularly in purchasing organisations, are a pervasive problem in LMICs. The case studies also highlighted the critical role of high-level political leadership in pursuing UHC policies and citizen support in sustaining these policies.

This series demonstrates the value of promoting greater sharing of experiences on UHC reforms across LMICs. It also identifies key areas of future research on health care financing in LMICs that would support progress towards UHC.
\end{abstract}

Keywords: Financial protection, Low- and middle-income countries, Policy analysis, Pooling, Purchasing, Revenue collection, Universal health coverage

\footnotetext{
*Correspondence: diane.mcintyre@uct.ac.za

${ }^{1}$ Health Economics Unit, Department of Public Health and Family Medicine, University of Cape Town, Anzio Road, Observatory, Cape Town 7925, South Africa

Full list of author information is available at the end of the article
} 


\section{Introduction}

There is growing policy momentum for countries to move towards universal health coverage (UHC), with resolutions calling for UHC being adopted in the World Health Assembly as well as the United Nations General Assembly during 2012. UHC was defined in the 2010 World Health Report as ensuring that everyone within a country can access the health services they need, which should be of sufficient quality to be effective, and providing all with financial protection from the costs of using health services [1].

With a few notable exceptions (such as the USA), UHC reforms are particularly focused on low- and middleincome countries (LMICs). As governments consider ways in which UHC goals can be achieved within their context, it is critical that there is greater documentation and sharing of experiences across LMICs in particular. It was with this in mind that the Alliance for Health Policy and Systems Research (World Health Organization) called for proposals to assess efforts towards universal financial risk protection in LMICs in 2009. Seven countries were selected for inclusion in this project and the results of the country case studies are reported in this series of articles.

This paper provides an overview of the key issues and lessons from these seven countries, supplemented by recent literature on UHC in LMICs. As the case studies were very diverse in terms of the issues of focus and methodological approaches, their findings were reviewed using two conceptual frameworks as a means of achieving some coherence. Firstly, information was extracted in relation to the key functions of health financing systems, namely revenue collection, pooling and purchasing, including the organisational arrangements for undertaking these functions [2]. The second framework is the policy analysis triangle, which considers the process, actors and context within which policy is developed and implemented [3]. The next section provides a brief overview of the specific reforms that were examined in each country case study, followed by a presentation of the key issues arising from the analysis of health financing functions and policy.

\section{Overview of case study countries}

Table 1 provides an overview of the reforms aimed at expanding health coverage in the seven countries included in this project. Table 2 presents economic, health status, and health systems indicators for these countries, providing insight into the very different contexts of each country.

Thailand and Costa Rica are both upper-middle-income countries that are regarded as having made remarkable progress towards UHC. They have the lowest infant and maternal mortality rates and greatest health service coverage levels (proxied by the percentage of deliveries made by a skilled attendant in Table 2), even though they do not have the highest doctor to population ratios. Costa Rica has particularly high levels of health care expenditure, with government funding being the major component in both countries, particularly in Thailand. Thailand is quite exceptional in having achieved UHC at relatively low cost, with government expenditure on health care being only $3.1 \%$ of GDP. These two countries are widely regarded as key examples that progress towards UHC is feasible not only for high-income countries; both countries embarked on ambitious programs of expanding coverage when still considered to be lower-middle or low-income countries. While they were able to make particularly strong progress at times of high economic growth, both countries protected and maintained government health spending levels during periods of economic downturn.

In Georgia and India, the countries with the second highest levels of economic development, recent initiatives have been introduced with the aim of extending health insurance coverage to the poorest population. In both countries, government revenue was used to pay insurance contributions for this group. In Georgia, private insurance schemes were used to provide cover [4], while in India both public and private insurance schemes were used [5]. While coverage of key health services, such as attended deliveries, is relatively high in Georgia, it remains low in India and health status indicators are far better in Georgia than in India. India has one of the lowest levels of government spending on health in the world.

The Tanzania and Nigeria case studies considered efforts to expand health insurance coverage. Both countries initiated mandatory health insurance by first covering civil servants, although in Nigeria, this was initially only for federal government employees [6]. The key focus in Nigeria has been to attempt to extend the National Health Insurance Scheme (NHIS) to government employees at state level. In Tanzania, the recent focus has been on extending coverage to those outside the formal-employment sector on a voluntary basis via the district level Community Health Funds (CHF), but with the National Health Insurance Fund (NHIF) taking over management of the CHF [7]. Both countries have high poverty rates, poor health status indicators and low levels of health service coverage. Nigeria has very low levels of government health expenditure, some of which is donor funded. Although Tanzania appears to have relatively high levels of government funding of health services, the majority of this is donor funded (donor funding accounts for $60 \%$ of all health care expenditure) [8].

Malawi has the lowest per capita income of all of the case study countries, a high poverty rate and poor health status indicators (although better than Tanzania and Nigeria). Again, the government expenditure on health reflected in Table 2 is deceptive, both because GDP is very low and nearly $90 \%$ of all health care expenditure in Malawi is funded by donors. Malawi is attempting to improve access to needed health services and provide some 
Table 1 Summary of reforms of focus and methodological approach in country case studies

\begin{tabular}{|c|c|c|}
\hline Country & Reforms of focus & Methodological approach \\
\hline \multirow[t]{5}{*}{ Costa Rica } & \multirow{4}{*}{$\begin{array}{l}\text { - Phased extension since } 1940 \text { of mandatory insurance coverage, } \\
\text { through the social security fund (Caja Costarricense de Seguro } \\
\text { Social: CCSS), to the entire population, beginning with formal- } \\
\text { sector employees in urban areas, then to rural employees, and } \\
\text { then to the self-employed and the poor (with government } \\
\text { paying the contribution for the poor from tax funds) }\end{array}$} & $\begin{array}{l}\text { - Qualitative study using document reviews, key-informant } \\
\text { interviews and focus group discussions (FGDs) }\end{array}$ \\
\hline & & • Historical lens applied \\
\hline & & - Used actor mapping framework \\
\hline & & - Used policy analysis triangle framework \\
\hline & $\begin{array}{l}\text { - Bringing hospitals under the control of the mandatory insurance } \\
\text { scheme and improving primary health care services }\end{array}$ & \\
\hline Georgia & $\begin{array}{l}\text { - Providing insurance coverage for the poor, using government } \\
\text { funds to pay private health insurance scheme contributions } \\
\text { (Medical Insurance for the Poor (MIP) program) }\end{array}$ & $\begin{array}{l}\text { - Mixed methods: analysis of secondary national household } \\
\text { survey data and primary qualitative data collection and } \\
\text { analysis (key-informant interviews and FGDs) }\end{array}$ \\
\hline India & $\begin{array}{l}\text { - Providing insurance coverage for the poor, using government } \\
\text { funds to pay contributions to health insurance schemes (public } \\
\text { or private) (Rashtriya Swasthya Bima Yojana: RSBY initiative) }\end{array}$ & $\begin{array}{l}\text { - Mixed methods: household survey of beneficiary households; } \\
\text { and key-informant interviews and FGDs }\end{array}$ \\
\hline \multirow[t]{2}{*}{ Malawi } & \multirow{2}{*}{$\begin{array}{l}\text { - Contracting (establishing Service Level Agreements - SLAs) with } \\
\text { faith-based providers to provide health services free of charge to } \\
\text { vulnerable populations, particularly for maternal and neonatal } \\
\text { services }\end{array}$} & - Case study design (facility-based SLA as the unit of analysis) \\
\hline & & - Mixed methods: exit survey and key-informant interviews \\
\hline \multirow[t]{2}{*}{ Nigeria } & \multirow{2}{*}{$\begin{array}{l}\text { - Efforts to extend coverage of the National Health Insurance } \\
\text { Scheme from the initial target membership of Federal civil } \\
\text { servants to State civil servants }\end{array}$} & - Case study design (state as the unit of analysis) \\
\hline & & $\begin{array}{l}\text { - Qualitative study using document review and key-informant } \\
\text { interviews }\end{array}$ \\
\hline \multirow[t]{2}{*}{ Tanzania } & \multirow{2}{*}{$\begin{array}{l}\text { - Transfer of management of district level community-based } \\
\text { voluntary health insurance schemes (Community Health Fund: } \\
\text { CHF) to the National Health Insurance Fund (NHIF), a mandatory } \\
\text { scheme initially established for civil servants but now open to } \\
\text { other formal-sector workers }\end{array}$} & - Case study design (district as the unit of analysis) \\
\hline & & $\begin{array}{l}\text { - Mixed methods: key-informant interviews and focus group } \\
\text { discussions; review of facility financial and utilisation records }\end{array}$ \\
\hline \multirow[t]{4}{*}{ Thailand } & \multirow{4}{*}{$\begin{array}{l}\text { - Phased extension of mandatory insurance coverage to entire } \\
\text { population }\end{array}$} & - Case study design (policy design feature as the unit of analysis) \\
\hline & & $\begin{array}{l}\text { - Qualitative study using key-informant interviews and document } \\
\text { reviews }\end{array}$ \\
\hline & & - Used policy analysis triangle framework \\
\hline & & - Used policy network approach \\
\hline
\end{tabular}

financial protection through contracting with faith-based facilities, which are often based in rural areas, to provide health services without charging a user fee to vulnerable populations, with a particular focus on maternal and neo-natal services [9].
This overview indicates that the countries included in this project are at very different stages of economic development. Only two countries can be considered to have come close to achieving UHC (Costa Rica and Thailand), yet all other countries are exploring ways of improving

Table 2 Key economic, health status, and health systems indicators for case study countries [8]

\begin{tabular}{|c|c|c|c|c|c|c|c|}
\hline & Costa Rica & Georgia & India & Malawi & Nigeria & Tanzania & Thailand \\
\hline Population (in thousands) (2009) & 4,579 & 4,260 & $1,198,003$ & 15,263 & 154,729 & 43,739 & 67,764 \\
\hline GNI per capita (PPP Int. \$) (2009) & 10,930 & 4,700 & 3,250 & 760 & 2,070 & 1,350 & 7,640 \\
\hline Poverty rate (\% population living on <PPP Int. \$1 per day) & $2 \%$ & $13.4 \%$ & $41.6 \%$ & $73.9 \%$ & $64.4 \%$ & $88.5 \%$ & $<2 \%$ \\
\hline Infant mortality per 1,000 live births (2009) & 10 & 26 & 50 & 69 & 86 & 68 & 12 \\
\hline Maternal mortality per 100,000 live births (2008) & 44 & 48 & 230 & 510 & 840 & 790 & 48 \\
\hline Deliveries by skilled attendant & $99 \%$ & $98 \%$ & $47 \%$ & $54 \%$ & $39 \%$ & $51 \%$ & $99 \%$ \\
\hline Doctor per 10,000 population & 13.2 & 45.4 & 6.0 & 0.2 & 4.0 & 0.1 & 3.0 \\
\hline Total health expenditure as \% GDP (2008) & $9.4 \%$ & $8.7 \%$ & $4.2 \%$ & $9.1 \%$ & $5.2 \%$ & $4.5 \%$ & $4.1 \%$ \\
\hline General government health expenditure as \% GDP (2008) & $6.3 \%$ & $2.7 \%$ & $1.4 \%$ & $5.5 \%$ & $1.9 \%$ & $3.3 \%$ & $3.1 \%$ \\
\hline Out-of-pocket payments as \% total health expenditure (2008) & $29 \%$ & $67 \%$ & $50 \%$ & $12 \%$ & $60 \%$ & $18 \%$ & $18 \%$ \\
\hline External resources for health as \% of total expenditure on health (2008) & $0.1 \%$ & $10.5 \%$ & $1.6 \%$ & $88.9 \%$ & $4.6 \%$ & $59.5 \%$ & $0.3 \%$ \\
\hline
\end{tabular}


access and financial protection, mainly by attempting to extend membership in health insurance schemes. In the rest of this paper, we consider key issues emerging from the diverse experiences of the seven different countries in relation to health care financing functions and policy process, actors and context.

\section{Health care financing functions}

Table 3 describes the health care financing policies examined in the country case studies in terms of the three health care financing functions, i.e., revenue collection, pooling and purchasing.

\section{Revenue collection and pooling issues}

All of the reforms in the country case studies in some way attempted to address the UHC goal of improving financial protection through reducing out-of-pocket payments. This was accompanied by explicit efforts to increase prepayment for health services, mainly through introducing or expanding health insurance coverage. However, Malawi attempted to protect vulnerable people from out-of-pocket payments at mission facilities, but without necessarily making efforts to increase pre-payment funds (such as generating more tax revenue or donor funds) to cover the cost of 'free' services. As a result, there are insufficient funds to pay for the contracted services, resulting in late or nonpayment of bills submitted by the mission facilities, which then stopped providing 'free' services [9].

Four of the countries - Costa Rica [10], Thailand, Tanzania and Nigeria - followed the example of some high-income countries and initiated efforts to improve financial protection by introducing mandatory health insurance schemes for certain groups of formal-sector workers, with some countries intending to ultimately cover the entire population with insurance schemes. In Costa Rica, mandatory insurance was initially restricted to workers in urban areas, whereas in the other three countries, the focus was on civil servants; however, in Nigeria, the focus was even narrower and initially only included federal government employees (Table 3). While Costa Rica took several decades to expand coverage to include most of the population, Thailand achieved universal financial protection of the population within 24 years [11]. There has been very slow progress in extending insurance scheme coverage in the other two countries, with only $4 \%$ of the population covered in Nigeria and $12 \%$ in Tanzania.

There are interesting differences in the approaches adopted in three of the countries to extending financial protection via insurance schemes to those outside formalsector employment (i.e., those involved in 'informal sector' and subsistence agriculture activities, the unemployed and the poor). While Costa Rica paid for CCSS (the mandatory insurance scheme) membership for these groups using general tax funds from when scheme membership was extended to them, Thailand and Tanzania attempted to extend insurance scheme membership to these groups on a voluntary, contributory basis (through the Voluntary Health Card Scheme introduced in 1983 in Thailand and the district level Community Health Fund (CHF) in Tanzania). Thailand ultimately decided to abandon this approach and tax funds were used to pay contributions for all those outside the formal-employment sector when the Universal Coverage Scheme (UCS) was introduced in 2002. Part of the reason for this change in policy was the recognition that attempting to extend coverage to those outside formal employment on a voluntary, contributory basis results in a substantial portion of the population remaining 'uncovered' (30\% in 2001 in Thailand) [11]. Tanzania has continued with the CHF as a voluntary contributory scheme, but has attempted to strengthen its management by contracting $\mathrm{CHF}$ management out to the NHIF, which has contributed to a doubling of CHF membership, but from a very low base of only $2 \%$ of the population [7].

There is widespread recognition that extending health insurance scheme coverage to the entire population requires substantial funding from general tax revenue to fully or partially subsidise contributions for those unable to pay themselves [1]. In this regard, it is noteworthy that in the two countries that are furthest along the path to UHC (Costa Rica and Thailand), government funding (which includes tax funding and mandatory insurance contributions) is the largest share of total health care expenditure. The Thai case study demonstrated how introducing the UCS was a mechanism for leveraging considerable increases in tax funding to ensure that the population outside of the formal sector were able to access a wide range of services of good quality.

A key question that requires further research is, given the magnitude of tax funds required to universalise health insurance coverage, is it worthwhile pursuing contributory schemes for those outside the formal sector in LMICs? In particular, the administrative efficiency of this approach (i.e., comparing the revenue generated to the costs of collecting revenue from this group) should be evaluated. Existing research indicates that it is a very regressive way of generating revenue for health care [12] and that gross revenue generation is quite low (for example, NHI contributions by those outside the formal-employment sector in Ghana account for only $5 \%$ of NHIF revenue) [13].

The seven country case studies raise important questions about the use of general tax revenue and other government funds (such as resources generated through royalties from the exploitation of oil reserves as in Nigeria). In particular, is it appropriate to prioritise the use of limited government resources to pay for health insurance coverage for civil servants, given that they are already a relatively privileged group? The issue of appropriate use of government funds 
Table 3 Overview of health financing systems in case study countries

\begin{tabular}{ll}
\hline Country & Revenue collection and pooling \\
\hline Costa Rica & - Tax funds pooled with mandatory insurance contributions \\
in the Caja Costarricense de Seguro Social (CCSS), which was \\
established in 1941 \\
- CCSS population coverage reached $88 \%$ in early 2000's \\
- General government revenue finances the Medical Insurance \\
for the Poor (MIP) program \\
- A proxy means-tested system is used to identify MIP \\
beneficiaries (i.e., poor households) \\
- Of the Georgian population, $20.5 \%$ are covered by MIP, 3.6\% \\
by civil servant insurance, $6.5 \%$ by other insurance (mainly \\
private, voluntary), and 69.4\% are not covered by insurance \\
- Under the Rashtriya Swasthya Bima Yojana (RSBY), households \\
on the national 'Below Poverty Line' list can join the insurance \\
scheme for a premium that is heavily subsidised by the \\
government (individuals pay \$0.6 per family per year) \\
- RSBY covers 30 million people (about $55 \%$ of those below \\
the poverty line) \\
- The health system in Malawi is mainly financed by government \\
tax revenue and high levels of donor funding \\
- Government tax funding subsidises Christian Health \\
Association of Malawi (CHAM) facilities as specified in Service \\
Level Agreement (SLA) contracts \\
- SLAs aim to deliver free health care to the most vulnerable \\
and under-served population through CHAM facilities \\
- 4\% of the population, mainly federal government employees \\
and their families, are covered by mandatory insurance through \\
the National Health Insurance Scheme (NHIS) introduced in \\
2005. Although expansion of the scheme to state government \\
employees was intended, only 3 states have done so \\
- NHIS is financed by contributions from employees (5\% of \\
basic salary) and employers (10\% of employees' basic salary) \\
Migeria
\end{tabular}

Tanzania $\quad$ - The National Health Insurance Fund (NHIF) was established in 1999 to cover civil servants and their dependents (about $5 \%$ of the population)

- The Social Health Insurance Benefit (SHIB) of the National Social Security Fund (NSSF), established in 2005, covers mainly private sector employees (about 1\% of the population)

- The Community Health Fund (CHF), rolled out nationally in 2001, focuses on those outside the formal sector in rural areas and a similar scheme called TIKA for the informal sector in urban areas (covers about 5\% of the population)

- The remainder of the population pay user fees when using a health service

- $\mathrm{CHF}$ is funded by member contributions. Matching funds, provided by Ministry of Health and Social Welfare, provides subsidies. Co-payment for the utilization of health services is required

Thailand $\quad$ - Three mandatory insurance schemes operate: the Civil Servant Medical Benefit Scheme (CSMBS) established in 1978. Social Security Scheme (SSS) for public and private sector employees; and the Universal Coverage Scheme (UCS), which covers the rest of the population (approximately 30\%), established in 2002

- Purchasing mainly through NHIS allocation of funds to Health Maintenance Organisations (HMOs) for the purchase of services from public and private providers for those covered by the NHIS

\section{Purchasing}

- CCSS purchases primary and hospital care for the entire population, irrespective of whether they make contributions to CCSS or not

- Private Insurance Companies (PICs), contracted by the government, purchase health services for MIP members

- The MIP benefit package includes: (1) emergency care and planned in-patient services; (2) chemotherapy and radiation therapy; (3) outpatient visits and limited diagnostic and laboratory tests; (4) compensation for delivery costs; and (5) outpatient prescription drugs

- Insurance companies purchase inpatient care for RSBY members from hospitals. State nodal agencies oversee insurance companies

- The RSBY package covers inpatient care up to $\$ 600$ per family per year

- Hospitals are paid on a diagnosis-related group (DRG) basis

- Purchasing mainly undertaken through Ministry of Health (MoH)established SLAs with the CHAM facilities at the district level

- MoH pays CHAM clinical staff salaries and provides medicines and other supplies

- Payment made by capitation for primary care services and fee-for-service for other levels of care (referral care must be pre-approved by HMOs)

- The NHI benefit package includes: out-patient care, prescriptions and diagnostic tests, maternity care, preventive medical and dental care, specialist consultation, in-patient care, eye examination and care, access to prostheses

- CHF purchase health services on behalf of members

- Benefit packages vary between CHFs, but usually only cover primary care outpatient services

- The NHIF and SHIB-NSSF purchase relatively comprehensive services from accredited public and private providers

- UCS purchases services from registered contractor providers, most commonly the district health system

- The benefit package is relatively comprehensive 


\section{Table 3 Overview of health financing systems in case study countries (Continued)}

$\begin{array}{ll}\text { - The UCS is funded by general Government tax revenue } & \begin{array}{l}\text { Providers are paid by capitation for outpatients; and global } \\ \text { budget and DRG for inpatients }\end{array} \\ \begin{array}{ll}\text { - The UCS initially had a } 30 \text { Baht co-payment, but this was } & \text { - The CSMBS and SSS similarly purchase comprehensive services } \\ \text { removed in } 2007 & \text { for their members }\end{array}\end{array}$

is especially important in countries such as Tanzania and Nigeria, where there is no political nor Constitutional commitment to universalism from the outset (in contrast to Costa Rica and Thailand). The Nigerian case study found that civil servants are unwilling to make any contributions to mandatory schemes themselves, and have an expectation that government should fully fund their participation in the NHIS [6]. Although the government in Tanzania offers to match contributions made to the $\mathrm{CHF}$ by those outside the formal-employment sector, this approach directs limited government funds to districts that have lower poverty levels (i.e., where more people outside the formalemployment sector have the ability-to-pay $\mathrm{CHF}$ contributions). The recent reforms of shifting management of $\mathrm{CHF}$ to the NHIF have exacerbated this situation in that claiming matching funds is now more complex and requires considerable management capacity, which tends to be worse in poorer districts [7].

Is it more appropriate to use government funds to target coverage for the poorest, as in India and Georgia (and Malawi, albeit not through insurance scheme coverage but through direct payments to faith-based facilities)? And more generally, is a targeting (as in India, Georgia and to some extent Malawi) or a universalist approach (particularly as in Thailand and Costa Rica) more effective? The Thai experience with the Voluntary Health Card Scheme highlights the problems of leakage and undercoverage when trying to identify and target subsidies to the poor and such problems contributed to the decision to move to the tax-funded UCS for all those outside the formal-employment sector. Empirical evidence suggests that for health care financing, the identification of the poorest or those most in need has proven to be a major challenge [14], and that the approach entails high administrative costs and significant administrative sophistication and capacity [15].

A related issue is the extent to which general tax funds are pooled with mandatory insurance contributions where such schemes are used to move towards UHC. Only one of the case study countries taking this route has a single pool of tax revenue and mandatory insurance contributions, namely Costa Rica's CCSS. However, a key challenge within Costa Rica is that the level of general tax funding is inadequate and there is a growing government debt to the CCSS [10]. While in Thailand tax funds are allocated to the UCS to purchase services for those outside formal-sector employment, there are two other mandatory insurance scheme pools and no mechanisms for promoting cross-subsidies across the three pools.

Some countries were found to have considerable fragmentation of funding pools. For example, Tanzania has two mandatory schemes for formal-sector workers (one for civil servants and another for workers in private companies). More importantly, the CHF consists of a scheme in each district, and as the country moves to having individual facility bank accounts, fund pools are being fragmented even more with each facility maintaining its own pool of CHF contributions. In Nigeria, although there is a single NHIS, funds are fragmented between a number of health maintenance organisations. Similarly, funds in Georgia and India are fragmented across a number of insurance schemes that provide coverage for the poor.

The international literature clearly highlights that fragmentation of fund pools should be minimised and the bigger the pool, the better $[1,16]$. There are several reasons for this, including that a single pool maximises income and risk cross-subsidies (i.e., from the rich to the poor and from the healthy to the ill). Thus, the extent of fragmentation of pools strongly influences the extent to which health care resources can be used to provide financial protection and access to needed care for everyone and to minimise disparities across socio-economic groups.

\section{Purchasing}

The case studies highlight considerable differences across countries in key elements of purchasing, including service benefits covered, the provider payment mechanisms used, the nature of the purchasing organisation (e.g., public or private, and single or multi-purchaser arrangement) and whether or not there is active or strategic purchasing of services (Table 3). The reforms in Georgia, India and Malawi were primarily around purchasing, as opposed to the revenue collection or pooling functions. However, the contracting of a number of different insurance schemes to purchase services for the poor in India and Georgia did result in fragmentation of pools.

\section{Service benefit issues}

A key issue around service benefits relates to the issue of fragmentation of funding pools, where benefit package differences across schemes often become an issue. For example, there are differences across the three schemes in Thailand and a key priority at present is trying to 
harmonise the benefit packages. However, even if the list of services covered by each scheme is identical, the lack of cross-subsidies across the three separate pools will continue to result in differences in resources available per person covered by the different schemes, and hence differences in the type, range and quality of services used across the schemes. This is illustrated by the large differences in per capita spending levels across the three schemes in 2011, of Thai Baht 2,278 in the UCS, 2,280 in the SSS but 14,239 in the CSMBS [17].

Shifting the management of the CHF to the NHIF in Tanzania highlighted the differences in service benefits between these schemes, and created expectations that CHF benefits would be increased to match those of the NHIF. However, this is not feasible given the low contribution rates and revenue for the $\mathrm{CHF}$, and equally low matching grants from government funds, and again highlights the problem of limiting cross-subsidies by fragmenting pools. The Tanzanian experience highlights the difficulty of integrating pools once separate pools have been established; there is opposition from civil servants to NHIF resources (much of which comes from general tax funding) being used to benefit CHF members [7]. This mirrors the experience in many Latin American countries where formalsector workers benefiting from mandatory insurance schemes were reluctant for their benefits to potentially be diluted through extending cover to those outside the formal sector [18].

The country studies also highlight the different implications of comprehensive versus limited service benefits. There are relatively low levels of out-of-pocket payments in both countries with comprehensive service benefits, Costa Rica and Thailand, and Thailand has evidence of considerable reductions in catastrophic spending when entitlement to comprehensive services with no user fees or co-payments was extended to the whole population [11]. In contrast, out-of-pocket payments remain high in most of the countries that offer limited service benefits (e.g., India only covering inpatient services; Georgia only partially covering outpatient drugs which is the major cause of catastrophic payments particularly for patients with chronic diseases). More importantly in India and Georgia, only the very poor are provided with financial protection, and even those who are members of these schemes do not always derive the benefits to which they are entitled.

While it may be ideal to provide comprehensive benefits, it is simply not feasible in lower-income countries at this time. Costa Rica and Thailand have the highest levels of economic development and so are better placed to cover comprehensive service benefits. Both countries now face challenges of sustaining accessible, quality services in the context of having created an entitlement for the entire population to comprehensive services.
Creating an entitlement to service benefits (whether comprehensive or limited) does not guarantee access to these services. The Indian experience clearly illustrates that those living further from health facilities were less able to use needed services, or where they did, had to incur higher levels of out-of-pocket payments [5]. An interesting aspect of the Georgian experience was that the private insurance schemes participating in the Medical Insurance for the Poor initiative were required to upgrade existing or construct new hospitals to improve physical access to services [4]. However, this was effectively paid for by the government as only $53 \%$ of the taxfunded contributions to these schemes were devoted to paying for services used by the poor and the rest used for infrastructure development and scheme administration. An important lesson from the Thai and Costa Rican experience is the strong and well-distributed service delivery base, particularly at the primary health care level, which has facilitated translating entitlements into improved levels of service use and health status.

\section{Provider payment mechanisms}

Several countries introduced capitation and diagnosisrelated group (DRG) payment mechanisms instead of fee-for-service, with varying degrees of success. In Nigeria, there was considerable discontent with capitation payments among primary care providers [6]. This was also the case with DRGs for inpatient care in India, where there is evidence that some doctors refuse to see Rashtriya Swasthya Bima Yojana (RSBY) - the insurance scheme for the poor - patients as they regard the DRGs as being too low [5]. In contrast, Thailand has been able to secure the buy-in of providers to being paid on a capitation and DRG basis for outpatient and inpatient care, respectively. Indeed, the fact that these payment mechanisms would be used along with a budget cap was critical in ensuring political support for the UCS.

There are two key factors that may contribute to these different experiences. Firstly, (private) providers' acceptance of payment in forms other than fee-for-service is likely to be influenced by the volume of services affected by the payment scheme. In Thailand, where services for the vast majority of the population are paid for via capitation and DRGs, providers have little choice but to accept this payment mechanism. In Nigeria and India, however, the majority of patients are outside of the schemes using such payment mechanisms and it is more feasible to refuse to treat patients on this basis or at least to complain vociferously and lobby for a change. This is a key benefit of having considerable purchasing power concentrated in a single purchaser, or a few large ones. Second, it is important that the capitation and DRG rates are fair and regularly updated. In Nigeria, the capitation rate has not been increased in six years [6], whereas in Thailand 
rates are adjusted annually. Lack of routine adjustment of payment rates has also created problems in Malawi, where the fee schedule has not been updated for five years [9]. There is a lack of clarity on what fees can be charged and some of the contracted hospitals charge whatever they feel appropriate, which has driven up costs considerably.

\section{Issues related to the purchasing organisation}

A critical issue is the capacity of the purchasing organisation and whether or not it engages in active or strategic purchasing. The Malawian case study illustrates the difficulties that can arise where there is poor capacity, in this case within the Ministry of Health and its district offices, which is purchasing services from faith-based facilities. The inability of the districts to make timely payments or supply drugs from the Ministry's Central Medical Stores has undermined the willingness and ability of mission facilities to provide the contracted services [9]. The capacity constraints are also evident in the limited supervision and monitoring of services provided by contracted facilities. In Tanzania, an explicit motivation for contracting the NHIF to manage the CHF was the greater management capacity within the NHIF. The case study highlights that supervision and monitoring of service quality, which is an important component of active or strategic purchasing, has improved under NHIF management.

India and Georgia made the decision to draw on the capacity within existing health insurance schemes by contracting the schemes to serve as purchasers. Unfortunately, the case studies provide no evidence of whether these schemes engaged in strategic purchasing or were more passive and simply paid providers. However, there is evidence that members of RSBY are not treated well by service providers, which suggests that the schemes are not playing an active role in clarifying their expectations of providers or monitoring service quality and taking remedial action where service provision is not acceptable. Even though capacity may exist within schemes in India, it appears to be relatively weak and there is a lack of capacity in the state nodal agencies, which supervise the insurance companies, as there are similar difficulties to that in Malawi in terms of timely payment of providers. Very little is known about how the health maintenance organisations that purchase services on behalf of NHIS members in Nigeria function, but it appears that there is limited effort to ensure that members receive the services and medicines that they need.

One of the key factors in Thailand's success is the capacity of the National Health Security Office (NHSO) and its strong and stable administration, which has been maintained through many changes in government [11]. NHSO is a public, autonomous body created to manage UCS and purchase health services. Although the NHSO is not a monopsony purchaser, as there are two other mandatory schemes operating in Thailand, it covers $75 \%$ of the population. The NHSO has used its purchasing power effectively to negotiate lower prices for key services (such as haemodialysis), medicines and medical devices.

\section{Policy related issues}

Some of the country case studies undertook a policy analysis, but all pointed to some health financing policy context, process or actors' issues. One of the clearest policy messages from the case studies is the importance of key windows of opportunity, such as those offered during election campaigns (which was important in introducing the UCS in Thailand and in the NHI in Ghana [19]), and the critical role of political leadership at the highest possible level. For example, President Calderon established the CCSS in Costa Rica in the 1940s and President Figueres played a critical role in ensuring that later reforms were not derailed by disagreements between opposing actors [10]. Similarly, Prime Minister Thaksin Shinawatra championed the introduction of the UCS in Thailand [11]. In contrast, in Nigeria, the lack of high-level political support, particularly from the governors in most states, has been an impediment to the NHIS being expanded from civil servants at the federal level to those at state level [6]. The Nigerian experience also highlights the importance of the political administration context; the high level of decentralisation of decision-making to state level has impeded implementation of the NHIS, which was initiated by the federal government.

Citizens have also been critical in sustaining UHC financing reforms. Both Thailand and Ghana have experienced multiple changes in government, including to governments run by the political party that was in opposition when specific reforms were introduced, yet the reforms have remained on track. This has largely been due to high levels of support from citizens. The Thai experience demonstrates that citizen action has also been important in extending the service benefit entitlements of the UCS. While this can create a problem for affordability of a UHC system (for example, if the public is constantly calling for the latest technology to be adopted), this was addressed in Thailand through careful use of technology assessment to ensure the most cost-effective interventions are adopted [11]. Public support has also been critical in sustaining the CCSS system in Costa Rica [10]. It is particularly interesting that the mobilisation of citizens around health issues is most evident in countries such as Costa Rica, Thailand and Ghana where there is an explicit policy commitment to universality from the outset of the health financing reforms.

A number of the country case studies highlighted important issues in relation to policy processes, particularly implementation processes. The need for careful preparation for policy implementation was highlighted in 
Tanzania, where the necessary legislation had not been put in place, hindering implementation. In Malawi, the policy was implemented in haste, without developing the required capacity at district level to manage the contracts or establishing mechanisms for monitoring and evaluation and for resolving contractual problems. The importance of communication about the policy to managers and front-line health workers, as well as the general public, to promote successful implementation is also illustrated in several of the case studies. In Tanzania, there was little awareness of the reforms at district and facility level, including among those involved in the CHF whose management structures were being changed, which again impeded implementation [7]. In India, there was little public communication resulting in very poor knowledge of entitlements amongst RSBY beneficiaries (many did not know that the card could be used for inpatient care, or did not know that they had to use specific hospitals that had been empaneled by their insurance scheme, etc.). This contributed to more than half of beneficiaries in the study area still making substantial out-of-pocket payments for inpatient care [5].

Paying careful attention to implementation processes, as well as active monitoring and evaluation of implementation practice can make the difference between simply creating entitlements to needed health services and financial protection and intended beneficiaries being able to realise these entitlements.

\section{Key issues for future research}

The findings from the seven country case studies highlight a number of areas for future research in health care financing and progress towards UHC.

Firstly, the results from the seven country case studies pose a number of important questions on revenue collection and pooling that require careful consideration and further examination, including:

- To what extent should contributory schemes (as opposed to using government revenue) be pursued in order to cover those outside the formal sector in low- and middle-income countries?

- What is the appropriate use of limited government resources, particularly relating to the prioritisation of government funds to pay for health insurance contributions for those who are relatively better off, such as civil servants?

- To what extent should a targeting approach in health care financing, which involves the use of means testing or proxy indicators to determine eligibility for social benefits, be pursued instead of a universalist approach, which considers the entire population to be the beneficiary of social benefits?
- What is the relative importance in UHC policies of pooling general tax funds with mandatory insurance contributions to create a single pool to maximise income and risk cross-subsidies?

There are three specific issues in the area of purchasing where further research is warranted. Firstly, the country case studies highlighted problems associated with limited benefit packages, particularly where some population groups have access to more comprehensive services. This highlights the need for more examination of the balance between cost, population and service coverage in progressing to UHC. Secondly, several countries introduced capitation and DRG payment mechanisms instead of fee-for-service, with varying degrees of success. Further examination of the factors influencing effective implementation of these provider payment mechanisms is required. Thirdly, as little is known about how best to achieve strategic purchasing, there is a need to further investigate the structure of the organisations and institutional arrangements that may facilitate strategic purchasing to ensure quality care provision and efficient use of resources by providers. This should include the relative effectiveness of autonomous public institutions (for example in Costa Rica and Thailand) compared with private insurance companies (such as in Georgia and some schemes in India) in undertaking strategic purchasing functions using public funds.

The findings from the seven country case studies also emphasise the importance of paying careful attention to the details of the policy process, during both the formulation and the implementation processes, in order for the health care financing policy to realise its intended outcomes. Many of the country studies used mixed methods and employed a case study approach to better understand how health care financing policies were implemented and to identify underlying factors that influenced the outcome of the policies. There is a great need for further research using a robust case study approach to provide rich information on how different health care financing policies have been implemented, what factors have contributed to achieving particular outcomes and in what contexts, and how to manage the process of health care financing policy implementation in order to achieve policy objectives and contribute to progressing towards UHC.

\footnotetext{
Abbreviations

CCSS: Caja Costarricense de Seguro Social: CHF: Community health funds; DRG: Diagnosis-related group; GDP: Gross domestic product; LMICs: Lowand middle-income countries; NHI: National health insurance; NHIF: National health insurance fund; NHIS: National health insurance scheme;

NHSO: National health security office; RSBY: Rashtriya Swasthya Bima Yojana; UCS: Universal coverage scheme; UHC: Universal health coverage.
} 


\section{Authors' contributions}

All authors were involved in providing extensive technical support to the country case studies on which this manuscript is based. All authors contributed to conceptualising and planning the structure and contents of this paper. DM prepared an initial draft and MKR, BKA and AH revised this draft and assisted in finalising the paper. All authors read and approved the final manuscript.

\section{Acknowledgements}

We would like to thank all members of the seven country case study research teams. We acknowledge that this programme of research was financially and technically supported by the Alliance for Health Policy and Systems Research, World Health Organisation (WHO). We also wish to acknowledge the inputs of the Health Systems Financing Department, WHO and the late Guy Carrin, in particular. We are also very grateful to Lucy Gilson for her extensive inputs during the protocol development stage. DM is supported by the South African Research Chairs Initiative of the Department of Science and Technology and National Research Foundation (NRF) of South Africa. Any opinion, finding and conclusion or recommendation expressed in this material is that of the authors and the NRF does not accept any liability in this regard.

\section{Author details}

${ }^{1}$ Health Economics Unit, Department of Public Health and Family Medicine, University of Cape Town, Anzio Road, Observatory, Cape Town 7925, South Africa. ${ }^{2}$ Alliance for Health Policy and Systems Research, World Health Organization, Geneva 27 1211, Switzerland.

Received: 19 June 2013 Accepted: 19 June 2013

Published: 24 September 2013

\section{References}

1. World Health Organisation: Health Systems Financing: The Path to Universal Coverage. World Health Report 2010. Geneva: WHO; 2010.

2. Kutzin J: A descriptive framework for country-level analysis of health care financing arrangements. Health Policy 2001, 56:171-204.

3. Walt $\mathrm{G}$, Gilson $\mathrm{L}$ : Reforming the health sector in developing countries: the central role of policy analysis. Health Policy Plan 1994, 9(4):353-370.

4. Zoidze A, Rukhadze N, Chkhatarashvili K, Gotsadze G: Promoting universal financial protection: health insurance for the poor in Georgia - A case study. Health Res Policy Syst In Press

5. Devadasan N, Seshadri T, Trivedi M, Criel B: Promoting universal financial protection: evidence from the Rashtriya Swasthya Bima Yojana (RSBY) in Gujarat. Health Res Policy Syst 2013, 11:29.

6. Onoka C, Onwujekwe O, Uzochukwu B, Ezumah N: Promoting universal financial protection: constraints and enabling factors in scaling-up coverage with social health insurance in Nigeria. Health Res Policy Syst 2013, 11:20.

7. Borghi J, Maluka S, Kuwawenaruwa A, Makawia S, Tantau J, Mtei G, Ally M, Macha J: Promoting universal financial protection: a case study of new management of community health insurance in Tanzania. Health Res Policy Syst 2013, 11:21.

8. World Health Organisation: World Health Statistics, 2011. Geneva: World Health Organisation; 2011.

9. Chirwa M, Kazanga I, Faedo G, Thomas S: Promoting universal financial protection: contracting faith-based health facilities to expand access Lessons learned from Malawi. Health Res Policy Syst 2013, 11:27.

10. Vargas J, Muiser J: Promoting universal financial protection: a policy analysis of introducing universal health coverage in Costa Rica (1940-2000). Health Res Policy Syst 2013, 11:11.

11. Tangcharoensathien V, Pitayarangsarit S, Patcharanarumol W, Prakongsai P, Sumalee $H$, Tosanguan J, Mills A: Promoting universal financial protection: how the Thai universal coverage scheme was designed to ensure equity. Health Res Policy Syst 2013, 11:25.

12. Mills A, Akazili J, Ataguba J, Borghi J, Garshong B, Makawia S, Mtei G, Harris B, Macha J, Meheus F, Mclntyre D: Equity in financing and use of health care in Ghana, South Africa and Tanzania: implications for paths to universal coverage. Lancet 2012, 380:126-133.

13. Akazili J, Garshong B, Aikins M, Gyapong J, Mclntyre D: Progressivity of health care financing and incidence of service benefits in Ghana. Health Policy Plan 2012, 27(Supplement 1):13-22.
14. Lagarde M, Palmer $\mathrm{N}$ : The impact of health financing strategies on access to health services in low- and middle-income countries (Protocol). Cochrane Database Syst Rev 2006, 3: CD006092.

15. Mkandawire T: Targeting and Universalism in poverty reduction. In Social Policy and Development Programme Paper Number 23. Geneva: United Nations Research Institute for Social Development; 2005.

16. Carrin G, James C: Reaching Universal Coverage via Social Health Insurance: Key Design Features in the Transition Period. Discussion Paper Number 2-2004. Geneva: World Health Organization; 2004.

17. Lindelow M, Hawkins L, Osornprasop S: Government spending and central-local relations in Thailand's health sector. In HNP Discussion Paper 75680. Washington, DC: World Bank; 2012.

18. Ensor T: Transition to Universal Coverage in Developing Countries: An Overview. York: Centre for Health Economics, University of York; 2001.

19. Agyepong I, Adjei S: Public social policy development and implementation: a case study of the Ghana National Health Insurance scheme. Health Policy Plan 2008, 23(2):150-160.

doi:10.1186/1478-4505-11-36

Cite this article as: Mclntyre et al.: Promoting universal financial protection: evidence from seven low- and middle-income countries on factors facilitating or hindering progress. Health Research Policy and Systems 2013 11:36.

\section{Submit your next manuscript to BioMed Central and take full advantage of:}

- Convenient online submission

- Thorough peer review

- No space constraints or color figure charges

- Immediate publication on acceptance

- Inclusion in PubMed, CAS, Scopus and Google Scholar

- Research which is freely available for redistribution

Submit your manuscript at www.biomedcentral.com/submit
() Biomed Central 